\title{
Patient Satisfaction with Proton-pump Inhibitors in a Tertiary Care Teaching Hospital
}

KOUSALYA PRABAHAR* ${ }^{*}$ G. ARUN ${ }^{1}$, SHANTHI VIJAYARAGHAVAN² ${ }^{2}$ H. SHARMA ${ }^{1}$, KEERTHI CHAITANYA ${ }^{1}$ AND

S. TEJA ${ }^{1}$

Department of Pharmacy Practice, Faculty of Pharmacy, University of Tabuk, Kingdom of Saudi Arabia, ${ }^{1}$ Department of Pharmacy Practice, Faculty of Pharmacy, ${ }^{2}$ Department of Gastroenterology, Sri Ramachandra University, Chennai, India

Prabahar, et al.: Patient Satisfaction with PPIs

The main objective of this study was to identify the safety, efficacy, cost of treatment and the overall patient satisfaction with proton-pump inhibitors. This prospective observational study was carried out for a period of 6 months in the In-patient Department of Gastroenterology. Using a validated treatment satisfaction questionnaire, patient satisfaction on the use of proton-pump inhibitors was assessed. The drug interactions, side effects and medication errors associated with proton-pump inhibitors were also detected. The collected data were statistically analyzed using SPSS 16.0 version software. Among 100 patients selected for the study, only $16 \%$ of the patients were completely satisfied with the overall usage of proton-pump inhibitors. There was a significant difference between male and female in the satisfaction index. There were no drug 
interactions found. Cost was the major factor, which affected the patient satisfaction with proton-pump inhibitors. The study results confirmed that proton-pump inhibitors are safe and effective in the therapy of gastrointestinal disorders.

Key words: Proton-pump inhibitors, satisfaction, gastric acid

The proton-pump inhibitors (PPIs) are the most effective inhibitors of gastric acid secretion available. They found to be highly effective when the parietal cell is stimulated to secrete acid postprandially, a relationship that has important clinical implications for timing of administration. Because the amount of $\mathrm{H}^{+} /$ $\mathrm{K}^{+}$-ATPase present in the parietal cell is greater after a prolonged fast, PPIs should be administered before the first meal of the day. In most individuals, once-daily dosing is sufficient to produce the desired level of acid inhibition, and a second dose, which is occasionally necessary, should be administered before the evening meal. PPIs should not be given concomitantly with $\mathrm{H}_{2}$ antagonists, prostaglandins, somatostatin analogues (octreotide), or other antisecretory agents because of the marked reduction in their acid inhibitory effects when administered simultaneously. A $\mathrm{H}_{2}$ antagonist can be used with a PPI, if there is a sufficient time interval between administration of the $\mathrm{H}_{2}$ antagonist and the PPI (although the precise minimal time interval has not been established). As an example, $\mathrm{a}_{2}$ antagonist can be taken before bedtime or during the night by individuals who report nocturnal breakthrough symptoms such as heartburn after taking a PPI in the morning ${ }^{[1-4]}$. In patients with Helicobacter pylori infection, PPI therapy causes corpus-predominant gastritis, which is frequently found in the background mucosa in patients with gastric cancer. The efficacy and safety of long-term PPI treatment have not been conclusive, thus there is a need to pay more attention to the additional pharmacological action of PPIs ${ }^{[5]}$. PPIs which profoundly diminish gastric acid production and secretion, have emerged as the most commonly prescribed medications for treatment of symptoms referable to the upper gastrointestinal tract ${ }^{[6,7]}$. Gastric acid is an important component in the pathophysiology of both gastro esophageal reflux disease (GERD) and peptic ulcer disease, and PPIs have proven efficacy in both relieving symptoms and preventing complications associated with these disorders ${ }^{[8,9]}$.

PPIs are used to treat diseases like GERD, prevention of non-steroidal antiinflammatory drug-induced injury, gastric ulcers, stress ulcers, gastritis, Zollinger-Ellison syndrome, prophylaxis of aspiration pneumonia and treatment of $H$. pylori infection as a part of triple therapy. Commonly used PPIs include omeprazole, lansoprazole, pantoprazole, rabeprazole and esomeprazole ${ }^{[10]}$.

PPIs cause remarkably few adverse effects. The most common are nausea, abdominal pain, constipation, flatulence, and diarrhea. Subacute myopathy, arthralgias, headaches, and rashes have also been reported. The PPIs have a long record of use worldwide without the emergence of major safety concerns ${ }^{[11]}$. Hence the present study was undertaken to assess the patient satisfaction with PPIs.

This prospective observational study was conducted in the In-patient Department of Gastroenterology, a tertiary care teaching hospital, after getting approval from the Institutional Ethics Committee (REF: CSP/13/OCT/31/167). One hundred patients who were admitted in Gastroenterology Department, who had received PPI, greater than $18 \mathrm{y}$ of age, who signed the informed consent form, who filled the treatment satisfaction questionnaire for use of PPIs were included in the study. Pregnant women and patients receiving intensive care management were excluded from the study. The informed consent form was prepared in English and vernacular language and the consent of all the participants were obtained. The patient information sheet was prepared in English and vernacular language and given to all the patients. The demographic details, diagnosis, medications were all entered in the data collection form. The patients were followed till discharge. Using a validated treatment satisfaction questionnaire for use of PPIs, the patient's satisfaction on the use of PPIs was assessed. It is a

This is an open access article distributed under the terms of the Creative Commons Attribution-NonCommercial-ShareAlike 3.0 License, which allows others to remix, tweak, and build upon the work non-commercially, as long as the author is credited and the new creations are licensed under the identical terms

Accepted 01 February 2018

Revised 06 June 2017

Received 30 August 2016

Indian J Pharm Sci 2018;80(2):379-383 
self-administered, disease-specific questionnaire for patients receiving treatment with PPIs. It was rated on a 7-point Likert scale like completely dissatisfied, very dissatisfied, somewhat dissatisfied, neither satisfied nor dissatisfied, somewhat satisfied, very satisfied, and completely satisfied.

Drug interactions, side effects, medication errors related to PPIs were also detected. Drug interactions were checked using computerized drug-drug interaction database system, UpToDate ${ }^{\circledR}$. The side effects were detected by observing the patient and questioning them. The medication errors were assessed by carefully observing the drug chart. The cost of treatment was also calculated.

The collected data was statistically analysed using SPSS 16.0 version software. The results were represented as number and percent wherever applicable. Crosstabulation method was used to identify the satisfaction index score of the number of patients using PPIs. The satisfaction difference between the male and female were calculated using Chi-square test.

The results of this survey provided an insight into the perception and practices of patients and physicians regarding PPI therapy for gastrointestinal disorders. One hundred patients were included in the study. There were 61 men and 39 women. Pantoprazole and omeprazole were the PPIs given in the hospital. Majority of patients $(23 \%)$ were in the age group of 28-37 y, followed by 22 patients in 48-57 y. In a study conducted by Robinson and Shaw only $22 \%$ of the patients were in the age group of $18-39 \mathrm{y}^{[12]}$. The age and gender-wise distribution of patients along with the dosage form of PPIs were summarized in Table 1. Seventy-nine patients were prescribed with pantoprazole injection and 58 with pantoprazole tablet. Five patients were prescribed with omeprazole capsule. The usage pattern of intravenous (IV) PPIs is similar to that reported by Alsultan et al. ${ }^{[13]}$ and Hoover et al. ${ }^{[14]}$. Among 100 patients, majority of the patients suffered with gastritis $n=54$, followed by 26 patients with liver disease. The primary diagnosis of the patients along with the gender distribution was shown in Table 2.

This study was undertaken to create awareness with a view of making clinical pharmacist, to identify and reduce the occurrence of specific drug-related problems. No studies have been performed comparing different PPIs with regard to primary adverse effect. By subjective and objective evidences, the side effects were detected. The side effects were observed only in patients prescribed with pantoprazole. Rashes were found in majority of patients $(\mathrm{n}=10)$ using pantoprazole injection, followed by flatulence in 5 patients with oral pantoprazole therapy. Injection caused more side effects than tablets or capsules. It is contrast to the study conducted by Chubineh and Birk, in which only $1-5 \%$ developed adverse effects ${ }^{[15]}$. The side effects of pantoprazole along with the dosage form were depicted in Table 3.

The duration of hospital stay along with the dosage form were summarized in Table 4. Patients receiving oral therapy with PPIs had shorter hospital stay when compared with IV therapy with PPIs and there is no evidence of difference in clinical outcome between oral and IV PPIs treatment. It is similar to the study conducted by Yen et al., in which there is no difference in the therapy with PPIs with IV or oral route ${ }^{[16]}$.

TABLE 1: AGE AND GENDER WISE DISTRIBUTION OF PATIENTS ALONG WITH THE DOSAGE FORM OF PPIs

\begin{tabular}{lcccccccccccc}
\hline \multirow{2}{*}{$\begin{array}{l}\text { Age } \\
\text { (years) }\end{array}$} & \multirow{2}{*}{$\begin{array}{c}\text { Total } \\
\text { (n) }\end{array}$} & \multicolumn{1}{c}{ Gender } & \multicolumn{4}{c}{} & \multicolumn{4}{c}{ Pantoprazole } & \multicolumn{4}{c}{ Omeprazole } \\
\cline { 3 - 15 } & & M & F & M & F & M & F & M & F & M & F \\
\hline $18-27$ & 16 & 6 & 10 & 3 & 7 & 3 & 7 & - & - & - & - \\
$28-37$ & 23 & 20 & 3 & 19 & 3 & 8 & 2 & - & - & - & - \\
$38-47$ & 21 & 15 & 6 & 14 & 1 & 11 & 3 & - & - & - & 3 \\
$48-57$ & 22 & 12 & 10 & 9 & 10 & 8 & 4 & - & - & 1 & - \\
$58-67$ & 10 & 5 & 5 & 3 & 4 & 3 & 3 & - & - & - & 1 \\
$68-77$ & 8 & 3 & 5 & 3 & 3 & 2 & 4 & - & - & - & - \\
\hline
\end{tabular}

IV: intravenous; PO: per oral; M: male; F: female

TABLE 2: DISTRIBUTION OF STUDY POPULATION BASED ON THE PRIMARY DIAGNOSIS

\begin{tabular}{lcc}
\hline Disease & \multicolumn{2}{c}{ Sex } \\
\cline { 2 - 3 } & $M(n=61)$ & $F(n=39)$ \\
\hline Gastritis & 27 & 27 \\
Liver disease & 22 & 4 \\
Hepatitis & 7 & 4 \\
Pancreatitis & 5 & 4 \\
\hline
\end{tabular}

M: Male; F: female

TABLE 3: SIDE EFFECTS OF PANTOPRAZOLE

\begin{tabular}{|c|c|c|c|}
\hline \multirow{2}{*}{ Side effects } & \multicolumn{2}{|c|}{ No. of patients } & \multirow{2}{*}{ Dosage form } \\
\hline & $M$ & $\mathbf{F}$ & \\
\hline Rashes & 8 & 2 & IV \\
\hline Dizziness & 0 & 2 & IV \\
\hline Nausea & 1 & 3 & IV \\
\hline Vomiting & 1 & 3 & IV \\
\hline Itching & 0 & 1 & IV \\
\hline Abdominal pain & 1 & 2 & PO \\
\hline Flatulence & 5 & 0 & $\mathrm{PO}$ \\
\hline
\end{tabular}

IV: intravenous; PO: per oral; M: male; F: female 
In this study, only pantoprazole was prescribed in injection form. The average cost of the medications was assessed. The average cost of IV pantoprazole per patient was 232.9 INR, 80.5 INR for oral pantoprazole and 54 INR for oral omeprazole. The average cost of the injection was more than tablets. It is similar to the study conducted by Hoover et al. ${ }^{[14]}$.

The treatment satisfaction questionnaire for the use of PPIs was assessed and it is given in Table 5. Cross tabulation method was used to identify the satisfaction index score of the number of patients using PPIs. Among 100 patients, only $16 \%$ of the patients (12\% of male and $4 \%$ of female) were somewhat satisfied to completely satisfied on the overall usage of PPIs. It is in contrast to the study conducted by Chey et al. in which $64.6 \%$ were completely satisfied ${ }^{[17]}$. There was a significant difference between male and female in the

TABLE 4: DURATION OF PATIENT'S HOSPITAL STAY USING PPIS

\begin{tabular}{lcc}
\hline \multirow{2}{*}{ Duration of hospital stay (days) } & \multicolumn{2}{c}{ No. of patients } \\
\cline { 2 - 3 } & IV & PO \\
\hline 2 & 5 & 4 \\
3 & 11 & 16 \\
4 & 18 & 7 \\
5 & 14 & 11 \\
6 & 12 & 9 \\
7 & 6 & 5 \\
8 & 9 & 5 \\
9 & 2 & 3 \\
10 & 2 & 3 \\
\hline
\end{tabular}

IV: Intravenous; PO: per oral satisfaction index, when compared using chi-square test $(\mathrm{p}=0.029)$. It is contrast to the study conducted by Chey et al. in which $68 \%$ of males and $61.1 \%$ of females reported being "very" or "completely" satisfied with their PPI therapy ${ }^{[17]}$. There were no drug interactions found.

Pantoprazole has been shown to improve health-related quality of life more effectively than $\mathrm{H}_{2}$ antagonists and with similar efficacy to other PPIs. Patients taking pantoprazole $40 \mathrm{mg} / \mathrm{d}$ had greater percent of symptom relief. PPIs have positive patient satisfaction rates in trial involving patient questionnaires aimed at evaluating health-related quality of life. Since pantoprazole is effective in controlling symptoms related to acidrelated diseases and improving health-related quality of life, interest has arisen in using pantoprazole on an as needed basis, rather than everyday doses ${ }^{[18]}$. In our study also, patients were taking pantoprazole $40 \mathrm{mg} / \mathrm{d}$.

About $64.6 \%$ of patients were 'very' or 'completely' satisfied and $35.4 \%$ of patients were 'somewhat satisfied' to 'completely dissatisfied' with their prescribed PPI therapy. However it is difficult to arrive at this conclusion since many patients were completely dissatisfied to somewhat dissatisfied with the cost of the medication and the long-term use of medications. None of the patients were completely satisfied in all the aspects of PPIs use. In our study, cost of the medication was the major factor in which majority of the patients were dissatisfied with PPI therapy. Dosing frequency affected satisfaction, as a significantly lower

\section{TABLE 5: TREATMENT SATISFACTION QUESTIONNAIRE FOR USE OF PPIS}

\begin{tabular}{lccccccc}
\hline Questions & CD & VD & SD & NSND & SS & VS & CS \\
\hline My medication gives me complete relief & 0 & 0 & 0 & 0 & 37 & 21 & 42 \\
My symptoms are completely under control & 0 & 0 & 0 & 2 & 39 & 24 & 35 \\
My medication allows me to sleep through the night & 0 & 0 & 1 & 0 & 17 & 20 & 62 \\
My medicine provides immediate symptom relief & 0 & 0 & 6 & 3 & 30 & 14 & 47 \\
I feel that the medication is the best one available for me & 0 & 0 & 0 & 4 & 21 & 17 & 58 \\
My medication allows me to do everything I want to do & 0 & 0 & 1 & 11 & 16 & 24 & 48 \\
My medication allows me to eat or drink anything I want & 0 & 1 & 2 & 2 & 36 & 16 & 43 \\
I expect immediate relief from my medication & 1 & 0 & 0 & 3 & 37 & 8 & 51 \\
I expect my medication to relieve all my symptoms & 0 & 1 & 2 & 6 & 20 & 20 & 51 \\
I am comfortable requesting specific medications from my physician & 1 & 0 & 7 & 4 & 23 & 19 & 46 \\
If my medication would cost twice as much, it would still be worth taking it & 7 & 2 & 17 & 10 & 36 & 7 & 21 \\
My medication is too expensive for the relief that I get from it & 0 & 6 & 24 & 8 & 37 & 6 & 19 \\
I am satisfied with the amount of money I pay for my medication & 1 & 5 & 5 & 9 & 52 & 6 & 22 \\
I worry about the side effects I have with my medication & 0 & 0 & 10 & 10 & 35 & 19 & 26 \\
I worry about the long-term use of my medication & 7 & 4 & 9 & 12 & 36 & 0 & 32 \\
I prefer to take my medication only when I have symptoms & 2 & 0 & 10 & 3 & 29 & 13 & 43 \\
I don't like taking medications every day & 0 & 0 & 14 & 4 & 39 & 0 & 43 \\
\hline
\end{tabular}

CS- completely dissatisfied; VD- very dissatisfied; SD- somewhat dissatisfied; NSND- neither satisfied nor dissatisfied; SS- somewhat satisfied; VS- very satisfied; CS- completely satisfied 
proportion of patients on twice-daily therapy were very or completely satisfied with therapy compared to patients on once-daily therapy. In our study, once-daily or twice-daily doses, all the patients were prescribed with $40 \mathrm{mg} / \mathrm{d}$, so dosing frequency does not affect the satisfaction index.

Two medication errors were found in our study. Both were prescription errors. The dosage form of injection pantoprazole was written as oral instead of IV. The available dose of pantoprazole is $20 / 40 \mathrm{mg}$, but it was wrongly mentioned as $150 \mathrm{mg}$. No drug interactions were found. Symptom relief is the strongest determinant of patient satisfaction in those who receive PPI therapy. Cost is the major factor, which affects the patient satisfaction with PPIs. IV PPIs are most costly than oral PPIs. IV PPIs can be converted to oral therapy, when applicable, since both dosage forms have equal bioavailability. Our study results confirm that PPIs are safe and effective in the therapy of gastrointestinal disorders.

\section{Acknowledgement:}

Authors thank the Tamilnadu Pharmaceutical Sciences Welfare Trust, Chennai, Tamilnadu, India, for awarding scholarship for this study (Ref: TNPSWT: 2013/2171).

\section{Conflicts of interest:}

There are no conflicts of interest.

\section{Financial support and sponsorship:}

Nil.

\section{REFERENCES}

1. Wolfe MM, Soll AH. The physiology of gastric acid secretion. N Engl J Med 1988;319(26):1707-15.

2. Wolfe MM, Sachs G. Acid suppression: Optimizing therapy for gastroduodenal ulcer healing, gastroesophageal reflux disease, and stress-related erosive syndrome. Gastroenterology 2000;118:S9-S31.

3. De Graef J, Woussen-Colle MC. Influence of the stimulation state of the parietal cells on the inhibitory effect of omeprazole on gastric acid secretion in dogs. Gastroenterology 1986;91(2):333-37.

4. Shin JM, Sachs G. Restoration of acid secretion following treatment with proton pump inhibitors. Gastroenterology 2002;123(5):1588-97.

5. Talley NJ, Vakil N. Practice Parameters Committee of the American College of Gastroenterology. Guidelines for the management of dyspepsia. Am J Gastroenterol 2005;100(10):2324-37.

6. Hungin AP, Rubin GP, O'Flanagan H. Long-term prescribing of proton pump inhibitors in general practice. Br J Gen Pract 1999;49(443):451-53.

7. De Vault KR, Castell DO. Updated guidelines for the diagnosis and treatment of gastroesophageal reflux disease. Am J Gastroenterol 2005;100(1):190-200.

8. Dean BB, Gano AD Jr, Knight K, Ofman JJ, Fass R. Effectiveness of proton pump inhibitors in non-erosive reflux disease. Clin Gastroenterol Hepatol 2004;2(8):656-64.

9. Lee S, Lee T, Lien H, Yeh H, Chang C, Ko C. Comparison of risk factors and disease severity between old and young patients with gastroesophageal reflux disease. Gastroenterology Res 2013;6(3):91-4

10. Hoogerwerf WA, Pasricha PJ. Pharmacotherapy of gastric acidity, peptic ulcers, and gastroesophageal reflux disease. In: Brunton LL, Lazo JS, Parker KL, editors. Goodman \& Gilman's The Pharmacological Basis of Therapeutics. 11th ed. New York: McGraw-Hill; 2006. p. 967-81.

11. Thomson ABR, Sauve MD, Kassam N, Kamitakahara H. Safety of the long-term use of proton pump inhibitors. World J Gastroenterol 2010;16(19):2323-30.

12. Robinson M, Shaw K. Proton pump inhibitor attitudes and usage: a patient survey. Pharm Ther J 2002;27:202-06.

13. Alsultan MS, Mayet AY, Malhani AA, Alshaikh MK. Pattern of intravenous proton pump inhibitors use in ICU and NonICU setting: A prospective observational study. Saudi J Gastroenterol 2010;16(4):275-79.

14. Hoover JG, Schumaker AL, Franklin KJ. Use of intravenous proton-pump inhibitors in a teaching hospital practice. Dig Dis Sci 2009;54(9):1947-52.

15. Chubineh S, Birk J. Proton pump inhibitors: the good, the bad, and the unwanted. South Med J 2012;105(11):613-18.

16. Yen HH, Yang CW, Su WW, Soon MS, Wu SS, Lin HJ. Oral versus intravenous proton pump inhibitors in preventing rebleeding for patients with peptic ulcer bleeding after successful endoscopic therapy. BMC Gastroenterol 2012;12:66.

17. Chey WD, Mody RR, Izat E. Patient and physician satisfaction with proton pump inhibitors (PPIs): are there opportunities for improvement? Dig Dis Sci 2010;55(12):3415-22.

18. Mathews S, Reid A, Tian C, Cai Q. An update on the use of pantoprazole as a treatment for gastroesophageal reflux disease. Clin Exp Gastroenterol 2010;3:11-6. 